\title{
New generalizations and explanations in language and gender research
}

\author{
P E N E L O P E E K ERT \\ Department of Linguistics \\ Stanford University \\ Palo Alto, CA 94305 \\ eckert@csli.stanford.edu
}

\author{
S A L LY M C C O N N E L L - G I N E T \\ Department of Linguistics \\ Cornell University \\ Ithaca, New York 14853 \\ smg9@cornell.edu
}

\section{A B S T R A C T}

Gendered linguistic practices emerge as people engage in social practices that construct them not only as girls or boys, women or men - but also as, e.g., Asian American or heterosexually active. Adequate generalizations about gendered language use and explanations of such generalizations require understanding the place of particular linguistic practices in the life of what Lave \& Wenger 1991 and Wenger 1998 call a Community of Practice: a group whose joint engagement in some activity or enterprise is sufficiently intensive to give rise over time to a repertoire of shared practices. Eckert's ethnographic/sociolinguistic work $(1989,1999)$ in preadolescent and adolescent communities of practice illustrates ways in which gender and other aspects of identity are co-constructed. We use these and other sociolinguistic data to suggest some of the many different kinds of generalizations, emerging from studies of language and gender, that look to communities of practice. (Community of Practice, gender, variation, social practice, local meaning, ethnographic sociolinguistics, identity construction)

At lunchtime in the spring of 1997, in an ethnically very heterogeneous junior high school in northern California, a crowd of Asian-American kids hangs out in a spot that is generally known in the school as "Asian Wall." Girls stand around in their high platform shoes, skinny bell-bottoms, and very small T-shirts, with hips cocked. As they toss their heads, their long sleek black hair (in some cases tinted brown) swishes across their waists, the slimness of which is emphasized by shiny belts. Some of them talk to, some lean on, quiet-demeanored boys with 
baggy jeans and baggy shirts, with hair long on the top and shaved at the bottom. Linda turns away from her group of friends with a characteristic tilted head toss, bringing her hair around her shoulders; and with an exaggerated high-rise intonation on the pronoun, she calls to a boy who's standing nearby, "What are You?" Another girl, Adrienne, who happens to be walking by, answers on his behalf: "He's Japanese-Filipino." The boy smiles silently, and Linda turns back to her friends.

What particularly concerns us in this vignette is the complex nature of social meaning in language use, and the challenge that it presents in the attempt to separate gender from other aspects of identity. This brief exchange was one move in the co-construction of gender, ethnicity, heterosexuality, life stage, and social status which is the order of business at Asian Wall. It was an individual move for those who spoke - Linda and Adrienne; for the Japanese-Filipino boy, who accepted the exchange with a silent smile, it was a public move in the more general construction of the Community of Practice (CofP) at Asian Wall.

A CofP is an aggregate of people who, united by a common enterprise, develop and share ways of doing things, ways of talking, beliefs, and values - in short, practices. A CofP can develop out of a formally or informally constituted enterprise: a choir, a gang, a secretarial pool, a family, a garage band, a friendship group, or an academic department. Once launched, it has its own life and develops its own trajectory. The development of shared practices emerges as the participants make meaning of their joint enterprise, and of themselves in relation to this enterprise. Individuals make sense of themselves and others through their forms of participation in and contributions to the community. The community as a whole constructs a joint sense of itself through the relation between its practices and those of other communities. Thus a CofP is not isolated and inward-looking, but shapes its participants' relations both among themselves and with the rest of the world.

What makes the Asian Wall crowd a CofP is the participants' joint engagement in constituting a viable crowd on a par with the other large, ethnically based crowds in school. Side by side with the Latinos and the African Americans, the Asian Americans constitute a major community of color in this school. Koreans, Vietnamese, Hmong, Japanese, Filipinos, and Chinese are not a homogeneous group by any standard. But just as the internal diversity of the African-American and Latino populations has been erased in most dominant American constructions of ethnicity, so the notion of "Asian American" is a coherent category entering public discourse. Those at Asian Wall embrace the construction of Asian Americanness not so much out of a sense of pre-existing commonality, as out of a shared need to construct a commonality around which they can join forces. In the face of the other dominant peer groups in school, the Asian-American students see the value of foregrounding their commonalities to increase their numbers and visibility, and hence to construct status. In this enterprise, knowing the differences among Asian cultures is as important as knowing the similarities; 
both kinds of knowledge distinguish participants from non-Asian Americans. At Asian Wall, different Asian-American ethnicities are emphasized - and some are even marginalized - in the self-conscious construction of unity around a particular set of differences.

The mixed-gender crowds (Eckert 1996, 1999) that emerge in pre-adolescence and early adolescence are the locus of heterosexual practice in the age group, and the visibility and status of the crowd is an important aspect of the co-construction of heterosexuality and social status. At the same time, new adolescent gender practices develop around heterosexuality - making gender, heterosexual social practice, social status, and age inseparable. In this heterogeneous school, race is part of the co-construction as well. In the crowd at Asian Wall, as in the Latino and African-American crowds nearby, the joint enterprise is this process of coconstruction. How, then, would we separate the construction of gender from that of status, heterosexuality, race, or age?

STYLE is the key to the development of this CofP; it exploits many kinds of resources, some of which are unique to the Asian-American community, and some shared with other groups. Among these is an emerging Asian-American speech style observable in California schools, which includes a variety of variables including vowels (Mendoza-Denton \& Iwai 1993), stress shift, speed, and intonation. Linda's exaggerated question intonation is among these, and is subtly distinct from the intonations heard in other crowds in the school. Linda's question and Adrienne's response are both public displays of boldness with boys - through aggressive questioning, and through the proprietary behavior of answering for boys. Neither of these is specific to Asian Wall; both arise more generally in late elementary-school heterosexual crowds. Both strategies establish girls as "players" in the heterosexual market. The content of the utterances, however, is specific to Asian Wall, and it constitutes one small step in the construction of community around Asian diversity.

This distinctive style of speaking interacts with styles of movement, dress, and other forms of social engagement that the junior high kids use in constituting themselves as Asian Americans. While some of the Latinas also have long black hair, they don't swish it in the same way, nor do they strive to emphasize smallness of waist and backside. The whole issue of tossing hair is a hot one among the school's African-American girls, as made evident in a girl's comment about one of her peers: "Look how she's tossing her hair - she thinks she's white." The emerging Asian-American style is embedded in the other aspects of life that are salient to seventh-graders, such as gender, heterosexuality, school orientation, gang orientation, and family relations. What brings them all together is not an abstract Asian Americanness, but the value of the CofP that has constituted itself around Asian Wall.

The combination of choices among stylistic resources makes the stylistic practice at Asian Wall what it is; the combination of concerns that bring together the CofP at Asian Wall imbues this style with its particular social meaning - which 
lies at the heart of sociolinguistics generally, and of the study of language and gender specifically. Our understanding of what it means to be male or female - in a particular group, in the community, in society, and in the world - underlies our interpretation of gender differentiation in language use. Sociolinguists have tended to focus on the more abstract level of social structure in their interpretation of meaning, seeking global generalizations which, they assume, supersede local dynamics. But if variations in language use that have no clear referential differences are used to encode local social meaning, then the nature of this meaning is a very central linguistic concern. To the extent that the CofP is the locus of this kind of meaning construction, it should be a key focus for sociolinguistic study.

\section{THE COMMUNITY OF PRACTICE}

Jean Lave and Etienne Wenger developed the CofP construct as the basis of a social theory of learning. (See Lave \& Wenger 1991 and Wenger 1998, which further develop and elaborate these ideas as an alternative to more traditional views of learning; see also the introductory article in this issue, by Holmes \& Meyerhoff, for a very useful comparison of the notion of the CofP to other analytic constructs used in sociolinguistics and in social theory.) The construct arose out of an examination of traditional apprenticeship, based on Lave's ethnographic work among Vai tailors in Liberia. In this work, it became obvious that tailors' apprentices learned tailoring not as a set of isolated or abstracted tailoring skills, but as part of an ever-evolving integration into the more general practices of the community, as defined by engagement in the master's atelier. This mutual engagement, and the learning that it embodies, is at the heart of the notion of CofP.

Every individual participates in a variety of communities of practice and is likely to have quite different forms of participation in each of them. Individuals negotiate identity - a place in the world - by negotiating their participation in multiple communities of practice. Gender emerges, in large measure, from differentiation in the kinds of CofP in which males and females tend to participate, and from the differentiated forms of participation that males and females tend to develop in mixed-gender communities of practice. Thus women are more likely to be members of secretarial pools, elementary-school staffs, and book clubs; men are more likely to be members of physics faculties, firefighting teams, and motorcycle gangs. Both males and females participate in families, church groups, and PTAs, but the terms of their participation tend to be highly differentiated.

Gender also emerges in relations among communities of practice. Such communities may overlap; some may subsume others; and quite separate communities of practice may function separately, but in quite direct relation to one another. A cheerleading squad and a football team constitute separate communities of practice, which come together around the honing of skills; however, they are jointly included in a more comprehensive CofP in which the cheerleaders' chief 
recognized function is support and admiration for the competitive athletic performance that is the chief function of the football team. The accumulation of such gendered pairings - not just of individuals, but of communities of practice (such as doctors and nurses, or bosses and secretaries) - is part of the institutionalization of gender.

The notion of CofP could extend to more global communities - such as academic fields, religions, or professions - whose size and dispersion means both that face-to-face interactions never link all the members, and that their focal "practices" are somewhat diffuse. However, the day-to-day meaning-making through which people construct identities takes place at a more local level. It is in more intensive communities that individuals are living their sense of themselves, and it is in such communities that being a linguist, a lawyer, or a Catholic tends to matter. It is in local activities and relations that individuals become, act like, and experience themselves as linguists, lawyers, or Catholics. Alignment or identification with the overarching "community" of linguists, lawyers, or Catholics may be a resource for this construction, and so may participation in subsets of these dispersed communities (such as the LSA, the Bar Association, or the parish). For this reason, Wenger 1998 has distinguished the face-to-face CofP from more diffuse communities of imagination or alignment.

Individuals construct identities through the resolution of their various forms of participation in various communities of practice. They may seek or avoid diversity, conflicts, or contradictions among their communities, or their forms of participation in them; some of these may be more or less central to their sense of who they are. They may also be more or less active or successful in managing their involvements. Participants come to each CofP with a history and a trajectory, a host of social and linguistic expectations from other sources, and a set of abilities. The extent and ways in which these are transformed depends on the nature of their engagement in the new CofP. Styles and frameworks developed in a CofP, which have been experientially very important to individuals in their previous histories, may be carried into interactions with strangers, or into communities of practice new to them. This is in part because the styles and frameworks constructed in experientially central communities of practice are likely to have become "second nature," sustained by a powerful set of dispositions (something like the habitus discussed in Bourdieu 1977); they may persist in directing tongue and brain even after the disappearance of their original function of facilitating individual participation as a community member in particular local practices. The communities of practice to which people belong at relatively early life stages probably have special importance for certain aspects of speech style and interpretation. Nonetheless, adults continue to construct and reconstruct themselves and others in many important ways as they participate in communities of practice throughout life.

In saying that language and gender are constructed in a CofP, we assume that those constructions take place within whatever constraints biology and social 
structures impose on community members. Thus Victoria Bergvall discusses, in this collection, the multifaceted character of gender, which has biological and social-structural dimensions, as well as the performative ones on which much of our discussion focuses. However, the bottom line is that forging sociolinguistic and gender identities is mainly accomplished as people engage directly with others in common ongoing projects - jointly developing shared ways of doing and thinking about things, shared ways of understanding. It is these projects, in the nitty-gritty details of what people are up to as they interact with one another on a sustained basis, which endow their styles of speech with social significance, and which give individuals frameworks for trying to coordinate their own actions and aims with those of other local community members. Although the notions of speech community and of social network have both been very useful in sociolinguistic inquiry, neither directs attention to what people are doing as they engage with one another. It is what people are DOING which gives their interactions real bite, and which constructs language and gender (and much more). As Holmes \& Meyerhoff observe in this collection, quality of contact matters in a CofP. What also matters is the detailed character of the contact: how it fits in the plans and projects of community members. It is the PRACTICE component of the CofP that makes it such a useful construct for language and gender analysts.

\section{IN SEARCH OF GENERALITY}

Some have charged that, by emphasizing the diversity of local practice (such as the events at Asian Wall), we are wallowing in complexity at the expense of searching for gender patterns. It is easy, of course, to miss general patterns as one attends to detailed particulars. However, a search for patterns that is not based on a variety of data is likely to yield a limited and quite expected set of generalizations. Most stereotypes have some connection to fact, however distorted and complex that connection might be; such generalizations are likely to fit best with practices of dominant social groups (and even there, they do not necessarily apply across the board). The more fundamental problem is that, if we search for patterns in language data unconnected to the practices of particular communities, we can at best get correlational information, and can never offer explanatory accounts. Such practices typically are relevant not only to gender, but at the same time to other aspects of social identity and other relations. A basic beginning in the search for valid generalizations with explanatory significance must be the examination of a wide variety of local communities of practice, along with serious consideration of apparent exceptions to candidate generalizations. The fact that gender is co-constructed with other aspects of identity is not just noise. Focusing on coconstruction not only avoids closing off serious analysis; such a focus may be the only way to uncover and begin to explain many important general patterns.

The crux of the issue is this: Because the social practices that construct gender are at the same time also constructing other aspects of identity - such as life stage, 
heterosexuality, ethnicity, or social class - illuminating generalizations involving gender are most likely to emerge when gender is examined not in isolation, but in interaction with other social variables. (This point was implied by McConnellGinet 1988 and Eckert 1990, and is explicitly developed in Eckert \& McConnellGinet 1992, 1995.) With a focus on sex difference, both sociolinguists and casual commentators have emerged with content-based or characterizing generalizations: Women are more conservative, more polite, more cooperative, or more egalitarian than men. But given that such generalizations almost never apply across the board in any community, and can be refuted on a grand scale in some communities of practice, we have two choices: to proclaim exceptions on no principled basis, or to look for quite different kinds of generalizations.

The search for across-the-board content generalizations is tied up with the survey-based research practice that has come to dominate the study of variation - a practice that has given the study of variation its great robustness, but has also bled it of its access to social meaning. The earliest modern quantitative study of variation, Labov's ethnographic study in Martha's Vineyard (1963), established that phonological variables can have very local meanings. Focusing on the island's prominent dialect feature, the centralization of the nucleus of (ay), Labov found that the use of centralized variants was concentrated in the speech of people who identified most strongly with the traditional island economy, and who were opposed to the increasing mainland influence on the island. Although conflict between local and global interests can be found in communities everywhere, it was particularly highlighted in Martha's Vineyard, at the time of Labov's study, because of the immediate threat of the mainland tourist trade to local life. While such conflict is ubiquitous, it is not at all clear that its local manifestations in variation are predictable. It is in examining a range of similar local situations that we can understand how and when this particular kind of global/local dynamic manifests itself in variation, and how local meanings are mobilized in the process.

Although Labov did not describe the nucleus-raisers of the Vineyard as a coherent unit, the correlations suggest that, at their core, there was a CofP based in the old Yankee community, around the local fishing enterprise. His study captured the intersection between interest, activity, and viewpoint that underlies a CofP; and one can assume that the practice that unites these communities includes not only ways of talking, but also activities, dress (and other patterns of consumption), concerns, and topics of talk. Yet while the traditional fishing practice emerged as the focus of centralization in Martha's Vineyard, one can only wonder how the viewpoint would have changed if Labov had examined gender. If he had, he might have found that the picture was as complex as the differences in men's and women's relation to, and experience of, events surrounding the social and economic changes taking place on the island. Which women felt better served by the mainland intrusion? For example, what kinds of opportunities did the encroaching tourist trade offer them? What was the nature of women's engagement in the traditional local economy, and how did that economy intersect with other things 
of importance to men and to women? Indeed, fishing may have been only part of the story. Our understanding of gender in variation, as in all aspects of language use, is to be found by generalizing from the local, rather than by ignoring it.

The concern with local meaning disappeared when sociolinguistics turned to large-scale survey studies, as pioneered in Labov's New York City study (1966). As the focus moved from the internal workings of communities to broad distributions of variation across large urban populations, the concern with local issues of identity was replaced by a concern with broad categorizations. Gender, then, came to be treated as an independent variable, the effect of which is expected to crosscut other categorizations such as class, age, and ethnicity.

Class has been the central social factor in large-scale sociolinguistic studies; and gender differences in variation have been treated as deriving from the genderbased character of language-users' place in the class system, and their RESPONSE to it. Within a general context of social stratification - with emphasis on a standard/ vernacular linguistic continuum which maps onto the socioeconomic continuum - generalizations about gender have homed in on women's place in that linguistic continuum, in relation to men. The simplest type of generalization would be that women's speech is more standard than men's, or less so. What is commonly claimed in variationist circles is that women's speech is more standard. The empirical findings, however, have been mixed. Women tend to be more standard across the board than men in their use of grammatical variables; however, where phonological variables are concerned, women tend to be more standard in their use of apparently stable variables, but they commonly lead in the use of nonstandard variables that represent sound change in progress (Labov 1990). Where women's speech is found to be more standard than men's, it is often claimed that this is because women are more status-conscious than men - or that they are unable to affect their socio-economic status through action in the marketplace, and so are constrained to rely on the accumulation of symbolic capital.

Some of these explanations make intuitive sense in light of gender practices in particular kinds of CofP. Trudgill 1972, observing that women used standard variants more than men in Norwich, England, suggested that women have few opportunities to affect their status through their actions in the workplace or other public arenas, and thus are constrained to rely on the symbolic realm to achieve upward mobility. To explain men's relatively less standard usage - and particularly middle-class men's adoption of vernacular variants that would be stigmatized in the standard language market - Trudgill invoked the notion of "covert prestige." Covert or non-legitimized prestige is associated with the prototypical working-class male image of toughness and strength. Thus women and men, according to Trudgill, are reaching into the standard and the vernacular linguistic markets, respectively, and are reaching for quite gender-specific ideals. As Ortner \& Whitehead 1981 have argued, gender itself is a system of prestige or social ranking (maleness is more highly valued than femaleness), and it is always crucially linked to other prestige systems. 
Deuchar 1989 has added a twist to Trudgill's perspective on women's maintenance of established standards, their "conservative correctness." She argues that women's place in society makes them more vulnerable to criticism, and that their more meticulous use of standard grammar can be less evidence of "social climbing" than a way of setting themselves "beyond reproach." A male manager can get away with using a non-standard negative now and then, but a female manager cannot. Deuchar focuses not on what women are reaching for, but on what they are fighting against: their need to do greater symbolic work than men simply to qualify in the marketplace, to avoid losing prestige.

There is also a more personal and specifically gendered danger associated with women's use of "tough" language in the societies that have been studied. Because cultural discourses in these societies overwhelmingly sexualize women, the kinds of "covert prestige" available to them are likely to take on sexual connotations. Thus, while the tough man is often viewed as powerful, the tough woman is likely to be viewed as a "slut." This perspective has particular meaning in the light of Wolfram's findings in his 1969 study of variation in the Detroit African-American community. In this community, women at all socio-economic levels are more conservative in the use of features of African American Vernacular English (AAVE) than are men; Wolfram's data show the most consistent gender pattern that has been found in any community study of variation. The variables that are included in his study (reflecting general practice in the study of AAVE) are grammatical ones, which are quite stable and highly stigmatized. It is worth considering that, among women in US society, African-American women are the most subject to denigration and to sexualization, and that a very systematic use of standard language may well be a response to their greater and more general social vulnerability. Although the general cultural setting is quite different, this defensive use of standard language by Detroit African-American women is not unlike what Brown 1980 has observed of women's politeness in a Mayan community; she argues that women use certain forms of politeness toward men as a strategy to avoid physical abuse.

In spite of the fact that women's speech is commonly more standard than men's, ignoring the many exceptions amounts to disqualifying significant segments of the population as "atypical." The cases in which women's speech is not more standard than men's are not only numerous but also quite telling, and the real nature of valid gender generalizations depends on fully accounting for these "exceptions" as well as for the "typical" pattern.

Generalizations about women's greater standardness are based on differences between grouped male and female speakers. In fact, in the communities studied, significant differences exist among women and among men, and there is also considerable overlap between male and female usage. Most speech community studies do not examine these intragroup differences and intergroup overlap; however, when we look at communities of practice, and at what women and men are doing in them, some insight may be forthcoming. One thing that is quite clear is 
that the different place of men and women in the LINGUISTIC MARKET constitutes an intervening variable (see Sankoff \& Laberge 1978 for discussion of this notion). Nichols showed this as far back as 1976, in a study of African-American women living in two different communities on an island off the South Carolina coast (see also Nichols 1980, 1983). These women's use of standard (non-creole) variables was directly connected to their employment opportunities, and to the linguistic requirements of jobs in the gender-segregated market. In one community, women participated in off-island employment opportunities, and these women led the men in use of standard variables. In the other community, women were not part of those larger markets, but were engaged on a daily basis only with other islanders; these women lagged behind the men in their households in the use of non-creole variants.

This study suggests a generalization based on participation in linguistic markets. Indeed, in industrial societies, standard language is often more crucial to women in the workplace than it is to men, because relatively standard language is a requirement of many of the jobs readily available to women: teacher, receptionist, secretary, or flight attendant. Teachers are credentialed by institutions where linguistic "correctness" is prized, and they are expected to provide models for the students in their charge; receptionists "represent" employers to "outsiders," and their "correctness" as they speak to those outsiders bolsters the employer's reputation; and so on. (Although we are focusing on variation, we note that the same employment opportunities also call for politeness, indirection, attention to affect, and other features of interactional style that have been essentialized as female.) The critical point is that the association of standard language skills with such jobs is not arbitrary, but is connected to the place of language use in the practices that are constitutive of the jobs. Although there are important differences in teachers' experiences in different communities of practice, there are nonetheless some important commonalities in the relevant sociolinguistic and gendered dimensions of practice in those communities. In contrast, standard language may actually be a detriment in a wide range of typically male jobs available to those from the same households: construction workers, truck drivers, or factory employees. Here language use is itself less central to occupational practice, and the most important linguistic interactions for workers are with workmates rather than with students, customers, or others who play quite a different role in the employment-centered CofP. The bottom line here is that the maintenance of a gender-differentiated employment market contributes to reifying gender as a set of polarized oppositions.

The practice of aggregating speakers, particularly according to sex and socioeconomic class, tends to homogenize a broad range of uses, masking extreme uses at either end of the variation spectrum. It also tends to yield the generalization that women are more standard because of gender arrangements in the workplace. But at least in part because of the normativity associated with this gender polarization, standard and vernacular language become feminized and masculin- 
ized respectively. Thus we cannot simply move our generalization from sex difference to kind of job.

This is particularly apparent in Labov's data on the fronting of (ae) and (aw) in Philadelphia (1990:234-5). In this study, Labov's focus on occupational groups, rather than on a composite socio-economic class, allows us to focus on the intersection between gender and job category. Labov correlates the fronting of (ae) with five occupational groups - unskilled, skilled, clerical, managerial, and professional - which constitute a continuum of status and of engagement in the standard language market. The correlations show a crossover between the men's and women's use of these variables, as the relation between men's and women's speech is reversed at the two ends of the occupational hierarchy: The speech of the unskilled women is more vernacular than that of male unskilled workers, while the speech of female managers and professionals is more standard than that of male managers and professionals. Thus women's overall range of use of these variables is greater than men's; and in the center of each of the opposed (standard and vernacular) linguistic markets, women lead men in the use of the appropriate variety.

Eckert's study of adolescents in the Detroit suburban area $(1989,1999)$ revealed a similar pattern in the two main urban variables, the backing of (uh) and the raising of the nucleus of (ay). Figures 1 and 2 compare the percentage of use of extreme variants of (uh) and (ay) in the speech of male and female participants in two class-based communities of practice in one high school: the jocks and the burnouts.

The two communities of practice constitute class-based cultures: The jocks are a middle-class community based in institutional (school) practice, while the burnouts are a locally based, urban-oriented, working-class community. As both figures show, jock girls are the most standard in their pronunciation of both variables, while burnout girls are the least. The boys' use of both variables follows the same patterns as the girls', with the jocks' speech more standard than the burnouts'. However, the girls' use of these variables shows wider variability than the boys'; the jock and burnout girls' values for both (ay) raising and (uh) backing constitute the linguistic extremes for the community. The boys' category differences are far smaller than the girls', unfolding within the wider envelope set by the girls' more extreme pronunciations. In both these cases, generalizations about the use of standard language can be linked to generalizations about women's position in society. In neither case, however, does the generalization about women's standard usage apply universally to women in the groups studied. In Eckert's research, standard language usage seems to be actively pursued by those young women who identify themselves with the school's corporate culture (and the middle-class aspirations it supports); it is roundly avoided by those who reject such an identification. Such data suggest an extension of the generalization that women have to do much more than men simply to maintain their place in the standard language market. We have argued elsewhere (Eckert \& McConnell- 


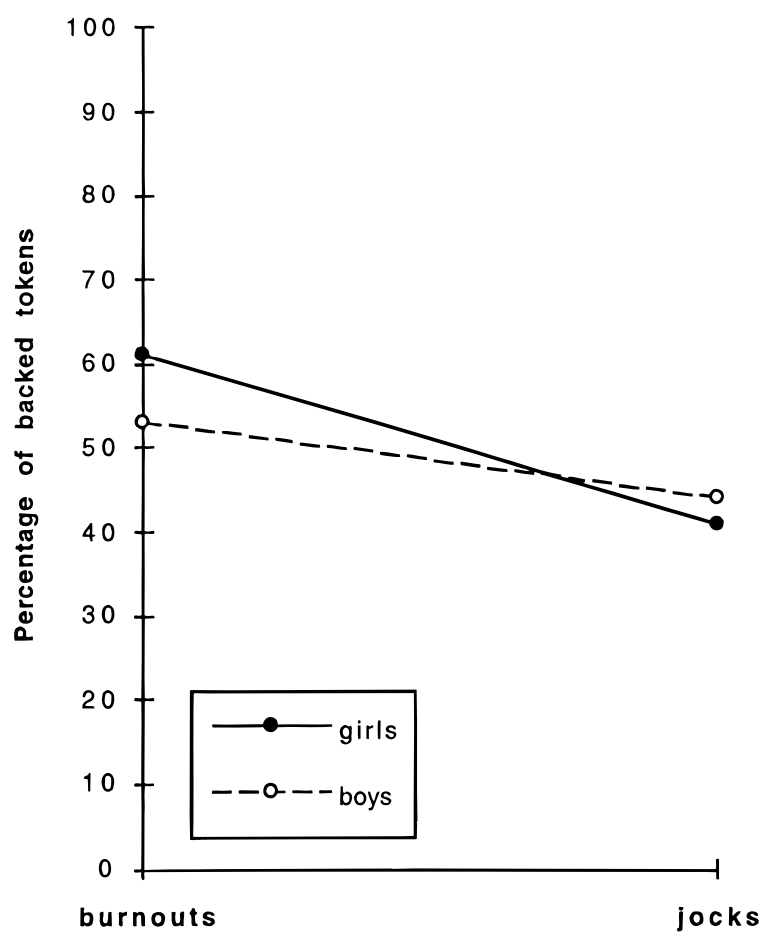

FIGURE 1: Percentage of backed tokens of (uh).

Ginet 1995) that women may have to use linguistic extremes in order to solidify their place, wherever it may be. Certainly the jock and the burnout girls, between them, covered a much wider range of possibilities than the boys. Brown 1980, on the basis of her study of politeness in a Mayan village, argued that women seemed to pay more attention to both positive and negative face, to put more of their energies into showing politeness of all forms. They were deferentially polite to men, protecting themselves against possible abuse; they were both warmly and deferentially polite to other women, enlisting their aid and also avoiding possible retribution.

It is tempting to conclude that women, being number two, simply try harder though even this more abstract generalization about the content of sex difference probably cannot be sustained. However, its advantage over the "Women are $x$, men are $y$ " kind of generalization is that it allows for diversity among women and among men. It also allows the possibility of extending beyond gender - tying gender patterns to more general phenomena, related to the sociolinguistic dynamics of dominant/subordinate groups and to other prestige systems. There undoubtedly are illuminating generalizations that will go somewhat deeper than the 


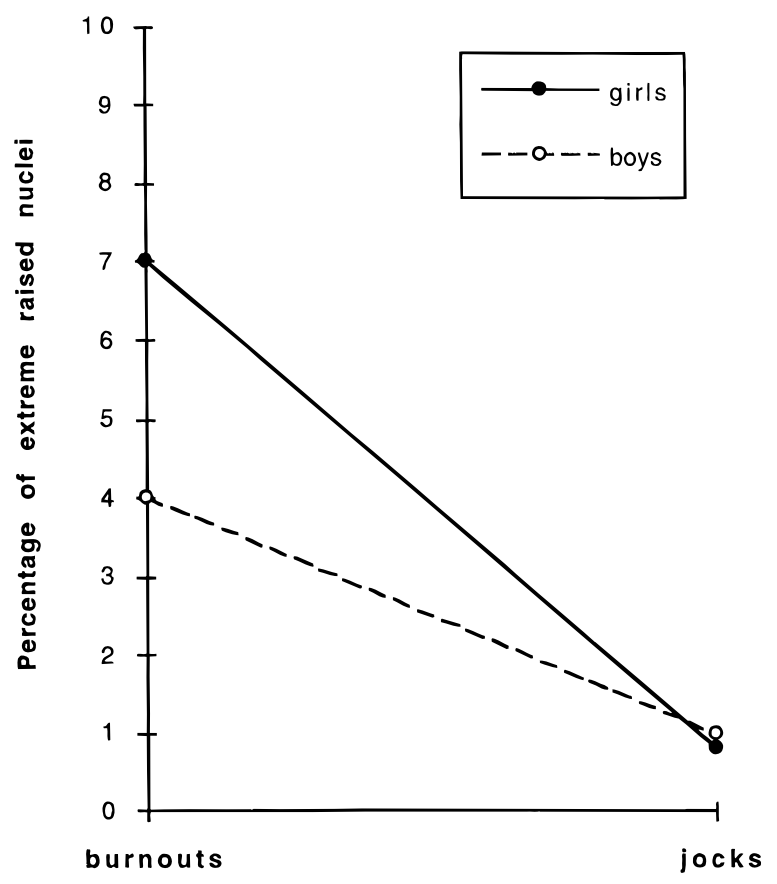

FIGURE 2: Percentage of extreme raised tokens of (ay).

inadequate characterizations exemplified by "Women use more standard forms, are more polite, etc." In communities where the notion of a linguistic "standard" is clearcut (cf. Haeri 1996, reviewed in this collection, for insightful discussion of the problematic character of the notion of "standard language"), we expect that these more adequate generalizations will link such forms to other features of social arrangements, including access to the linguistic market - and also to more general ways in which gender is linked to social value and prestige, and to ways of enhancing one's own ranking, of securing one's own "place."

Of course, the "Women are more standard" generalization has long co-existed with another, apparently incompatible generalization: Women lead in certain ongoing sound changes that bring new vernacular variants into a community. This generalization too is known to have exceptions, such as the Labov study on Martha's Vineyard. But many studies uphold it, such as the work of the Milroys and their colleagues in Tyneside (reported by Milroy et al. 1994). As with "Women are more standard," a number of explanations have been offered for the generalization about women's lead in ongoing sound change; these include the observation that such changes often originate with the young, and that women as mothers are more exposed to the speech of the young innovators than are their adult male 
peers (cf. Labov 1990). Parenting practices may or may not be significant; however, adequate explanations for such recurring patterns must come from a detailed examination of the way in which particular speech patterns fit with the gendered practices of local communities, and the values and interests of members of those communities.

\section{O N C L US I O N}

Whatever new generalizations about language and gender may ultimately be made, they will shift the focus - away from attributes, and toward actions, strategies, and values; away from properties that women and men might have, and toward their social practices and social relations, both same-sex and cross-sex. The emphasis will be on men and women as active participants in various communities of practice. Some of these generalizations are articulated in the other articles in this collection. Thus the shift from attributes to actions and stances is apparent in Miriam Meyerhoff's paper. In her discussion of women's overwhelmingly greater use of empathetic linguistic strategies, she does not say that Vanuatu women are more empathetic than men; rather, she suggests that woman's commonly available social roles, as compared with those of men, give such strategies prominence in women's speech. "Social roles" are closely linked to what we have elsewhere spoken of as forms of participation in a CofP: We might say that these Bislamaspeaking women frequently are the kinds of members for whom showing empathy "fits" well with their own and others' goals, within the communities of practice to which they belong. This seems like a generalization that might emerge from looking at different but, in certain ways, quite similar (and closely connected) communities of practice in Vanuatu, e.g. at different households. It is possible, of course, that the explanation is somewhat different. For example, perhaps only women belong to communities of practice whose members engage in such empathetic practices. If this latter is the right generalization, then we would expect to find the empathetic forms confined mainly to linguistic exchanges within these all-female communities of practice - or, if used in women's comments to men, not correctly interpreted as empathetic but perhaps heard as apologetic.

Although some gendered practices originate in essentially single-sex communities of practice, many (perhaps most) do not. They arise in communities of practice where the different forms of membership are gendered. Alice Freed notes that a pregnant woman is typically a member of a CofP that includes, among others, her doctor and the baby's father. Here we find gendered forms of membership in the CofP; some interesting generalizations may emerge from comparing a number of such communities that are alike in the general forms of membership they offer, and in the enterprises on which the community centers.

In contrast, Mary Bucholtz looks at relations among distinct female communities of practice, focusing on non-conforming women. The teen-age nerds whom she describes have rejected the forms of membership available to them in the 
most visible and influential existing female communities of practice, and they instead constitute themselves as members of an alternative female CofP. A critical generalization that emerges here is the enormous significance of relations among different female communities of practice: The nerd girls are specifically constituting themselves as girls of a different stripe from both the jock and the burnout girls.

Susan Ehrlich too examines differences among women, and shows that many strikingly different forms of membership may be open to women within a particular CofP. The student plaintiff and her faculty "judge," in a university hearing on sexual assault, are quite different kinds of members of that CofP, with different interpretive authority attached to their distinct community positions. At the same time, Ehrlich notes that the common sex of these distinct kinds of community members can be interpreted by others as overshadowing these differences within the local CofP - as automatically creating transcendent common interests and goals. Perhaps what is going on here is the postulation of a more global community centered on cross-sex antagonism in the university, where the main difference in forms of membership emerges from the sex of members. But it may be more generally true that many communities engage in social practices that constitute the categories of women and men as overriding other distinctions among community members; such practices reify gender polarities. However this phenomenon should be described, Ehrlich points to some of the kinds of linguistic practice that are important, in particular communities, in constituting gender categories themselves.

We cannot discuss in detail the articles in this collection, but we want to make the point that many different kinds of generalizations can emerge from studies of language and gender that look to the CofP concept. Giving fundamental importance to the study of local communities of practice does not in itself show where generalizations may be found - nor, of course, what generalizations may be found. Even a single study of a local CofP, however, can suggest significant generalizations about language and gender which can be explored in other community studies, and perhaps with other methods (e.g. survey data). Some of those generalizations may deal with differences between women's and men's speech; others may deal with differences in speech among women or among men, and the ways these differences connect to other social distinctions; and others may deal with how speakers use language, along with other social resources, to construct both local and global gender arrangements. Specific features of the overarching gender structures in a culture may well be connected with specific ways that gender and language interact in different communities of practice situated in that culture. (Compare Victoria Bergvall's discussion, in this collection, of what she dubs the third dimension of gender what is "thrust upon" us, what derives from institutional and cultural arrangements that constrain, in very similar ways, many otherwise quite different local communities of practice.) The kind of research that will allow us to explore 
such connections is still in its infancy; it will require not only insight into linguistic possibilities, but also richer conceptions of gender than have been available for sociolinguistic studies in the past.

Studies of gender and language in local communities of practice do not stand alone. It is vital that they be compared with one another, so that general patterns can be clarified. It is also vital that they be supplemented by consideration of such matters as inter-community relations, institutional forces, and individual differences. Nonetheless, studies like those in this collection can point us toward new generalizations and more adequate explanations.

\section{R E FERENCES}

Bourdieu, Pierre (1977). Outline of a theory of practice. Cambridge \& New York: Cambridge University Press.

Brown, Penelope (1980). How and why are women more polite: Some evidence from a Mayan community. In Sally McConnell-Ginet et al. (eds.), 111-36. [Reprinted in slightly abridged form in Jennifer Coates (ed.), Language and gender: A reader, 91-99. Oxford: Blackwell, 1998.]

Deuchar, Margaret (1989). A pragmatic account of women's use of standard speech. In Jennifer Coates \& Deborah Cameron (eds.), Women in their speech communities, 27-32. London: Longman.

Eckert, Penelope. (1989). Jocks and burnouts: Social categories and identity in the high school. New York: Teachers College Press.

(1990). The whole woman: Sex and gender differences in variation. Language Variation and Change 1:245-67.

(1996). Vowels and nail polish: The emergence of linguistic style in the pre-adolescent heterosexual marketplace. In Natasha Warner et al. (eds.), Gender and belief systems: Proceedings of the Fourth Berkeley Women and Language Conference, 183-90. Berkeley: Berkeley Women and Language Group.

(1999). Variation as social practice. Oxford: Blackwell.

, \& Sally McConnell-Ginet (1992). Think practically and look locally: Language and gender as community-based practice. Annual Review of Anthropology 21:461-90.

(1995). Constructing meaning, constructing selves: Snapshots of language, gender, and class from Belten High. In Kira Hall \& Mary Bucholtz (eds.), Gender articulated: Language and the socially constructed self, 459-507. London: Routledge.

Haeri, Niloofar (1996). The sociolinguistic market of Cairo: Gender, class, and education. London: Kegan Paul.

Labov, William (1963). The social motivation of a sound change. Word 19:273-307. [Reprinted in his Sociolinguistic patterns, 1-42. Philadelphia: University of Pennsylvania Press, 1972.] (1966). The social stratification of English in New York City. Washington, DC: Center for Applied Linguistics.

(1990). The intersection of sex and social class in the course of linguistic change. Language Variation and Change 2:205-51.

Lave, Jean, \& Wenger, Etienne (1991). Situated learning: Legitimate peripheral participation. Cambridge \& New York: Cambridge University Press.

McConnell-Ginet, Sally (1988). Language and gender. In Frederick J. Newmeyer (ed.), Linguistics: The Cambridge Survey, IV:75-99. Cambridge \& New York: Cambridge University Press. , et al. (1980), eds. Women and language in literature and society. New York: Praeger.

Mendoza-Denton, Norma, \& Iwai, Melissa (1993). "They speak more caucasian": Generational differences in the speech of Japanese-Americans. In Robin Queen \& Rusty Barrett (eds.), Proceedings of the First Annual Symposium About Language and Society - Austin (SALSA), 58-67. Austin: University of Texas.

Milroy, James; Milroy, Lesley; Hartley, Sue; \& Walshaw, David (1994). Glottal stops and Tyneside 
glottalization: Competing patterns of variation and change in British English. Language Variation and Change 6:327-57.

Nichols, Patricia C. (1976). Linguistic change in Gullah: Sex, age, and mobility. Dissertation, Stanford University. 49.

(1980). Women in their speech communities. In Sally McConnell-Ginet et al. (eds.), 1980:140_-

(1983). Linguistic options and choices for Black women in the rural South. In Barrie Thorne et al. (eds.), Language, gender and society, 54-68. Rowley, MA: Newbury House.

Ortner, Sherry, \& Whitehead, Harriet (1981). Introduction: Accounting for sexual meanings. In Sherry Ortner \& Harriet Whitehead (eds.), Sexual meanings: The cultural construction of gender and sexuality, 1-27. Cambridge \& New York: Cambridge University Press.

Sankoff, David, \& Laberge, Suzanne (1978). The linguistic market and the statistical explanation of variability. In David Sankoff (ed.), Linguistic variation: Models and methods, 239-50. New York: Academic Press.

Trudgill, Peter (1972). Sex, covert prestige and linguistic change in the urban British English of Norwich. Language in Society 1:179-95.

Wenger, Etienne (1998). Communities of practice. Cambridge \& New York: Cambridge University Press.

Wolfram, Walt (1969). A sociolinguistic description of Detroit Negro speech. Washington, DC: Center for Applied Linguistics. 